\title{
Недоходная бедность пожилых
}

П. КУЗНЕЦОВА, ИНСтИТУТ социальНого аналиЗа и прогНозИрования РАНХиГС, Москва.

В работе на данных репрезентативного обследования ветеранов труда оценивается недоходная бедность пожилых. Рассматриваются шесть возможных направлений депривации (питание, финансовое благосостояние, имущество, жилье, здоровье и социальная интеграция), а также депривация в целом. Несмотря на низкий уровень официальной бедности, пожилые граждане часто вынуждены ограничивать себя в питании, испытывают трудности с оплатой лекарств и медицинских услуг, страдают от недостаточной помощи в быту и отсутствия финансовой поддержки. Риск испытывать недоходную бедность растет с возрастом респондентов, в то время как наличие партнера, присутствие в домохозяйстве работающих, а также высокий уровень образования существенно его снижают. Ключевые слова: бедность, депривация, пожилые, риски бедности, социальная исключенность, многомерный анализ

Тема многостороннего измерения бедности весьма популярна в международной и российской исследовательской практике. На смену привычному и закрепленному в официальной статистике определению бедности как дефицита доходов приходит концепция многокритериальной, или многомерной бедности, определяемой как целый ряд проблем не только финансового плана, но и связанных с тяжелыми условиями проживания, низким качеством питания, недостаточной социальной интеграцией и т.д. Несмотря на то, что доходную бедность легко зафиксировать, измерить и провести международные сравнения, социально неприемлемый уровень доходов все чаще воспринимается как лишь одно из проявлений бедности.

Особенно заметны различия между доходной и недоходной бедностью пожилых. Уровень доходной бедности среди лиц пожилого возраста существенно ниже общенациональных значений, поскольку российские пенсионеры законодательно выведены за пределы бедности. Однако самооценки пожилыми гражданами своего материального положения не столь оптимистичны. Так, в 2015 г., по данным обследования бюджетов домашних хозяйств (ОБДХ) Росстата, 29\% домохозяйств пенсионеров, оценивая свое финансовое положение, заявили, что на еду денег им хватает, но покупать одежду они не могут себе позволить, что существенно выше, чем в среднем по выборке (19\%). 
В статье представлены результаты исследования, проведенного на данных репрезентативного опроса домохозяйств, в которых проживают ветераны труда. В ходе исследования даны оценки депривации по таким направлениям, как питание, финансовое благосостояние, имущество, жилье, здоровье и социальная интеграция, а также недоходной бедности в целом. Был проведен анализ территориальных, домохозяйственных и индивидуальных факторов, оказывающих влияние на риски депривации различного вида.

\section{Как измерить бедность?}

Понятие бедности усложнялось по мере накопления информации о различных лишениях, не связанных напрямую с уровнем дохода. Одним из аргументов в пользу более внимательного изучения деприваций стало многократно зафиксированное в эмпирических исследованиях существенное расхождение между монетарной и немонетарной бедностью: люди с низкими доходами не всегда испытывают лишения и, наоборот, финансовое благополучие не всегда позволяет избежать рисков депривации [Townsend, 2002; Atkinson et al., 2002; «Бедность: альтернативные подходы...», 1998; Овчарова, 2012].

С усложнением концепции бедности возникла проблема ее адекватного измерения. На данный момент не существует способа, который бы однозначно устраивал большинство исследователей. В то же время требования к подобным мерам сформулировать несложно: с одной стороны, они должны учитывать многообразие проявлений депривации и социальной исключенности, а с другой - допускать однозначную и не слишком сложную интерпретацию.

Представленные в современной экономической литературе способы измерения многомерной бедности используют два основных подхода. Первый предполагает отбор нескольких направлений, соответствующих различным сферам жизни человека и последующую разработку нескольких индексов, определяющих черту и состояние бедности для каждого из выбранных направлений. Второй подход заключается в разработке единого показателя, агрегирующего разнородную информацию по различным направлениям. В качестве примера можно привести индекс многомерной бедности (Multidimensional Poverty Index, cм. [Alkire and Santos, 2012]), который используется в межстрановых расчетах ОOH [UNDP, 2016], а также индекс бедности и социальной исключенности AROPE, рассчитываемый Евростатом [Guio et al, 2012].

Стремление исследователей и специалистов национальных статистических агентств к упрощению оценок и сведению многообразия бедности к одному показателю неоднократно подвергалось критике [Ravallion, 2011; Bourguignon and Chakravarty, 2003]. Противники разработки единого показателя бедности отмечают несопоставимость агрегируемых показателей (например, детской смертности и оснащенности жилья коммунальными удобствами), а также неоднозначную интерпретацию и недостаточную устойчивость получаемых результатов.

В случае, когда бедность определяется с помощью наличия у индивидуума или домохозяйства деприваций определенного типа, ее измерение сводится к расчету индекса, агрегирующего информацию ряда индикаторов, и включает в себя следующие шаги: а) отбор направлений оценки и набора показателей по каждому из них; б) разработку методики расчета индекса, включая выбор процедуры взвешивания отдельных показателей (с учетом их важности для данного вида лишений); в) определение черты депривации, отделяющую тех, кто испытывает данный вид депривации, от всех остальных [Coromaldi and Zoli, 2012].

В число индикаторов депривации могут включаться как объективные, так и субъективные показатели, предполагающие самооценку респондентами жизненных обстоятельств, в которых они находятся. Показатели занятости и образования могут интерпретироваться по-разному. Часто они причисляются к показателям депривации: так, например, в концепции развития ЕC до 2020 г. бедность оценивается по трем основным компонентам-доходная бедность, материальная депривация и недостаточная интенсивность работы (см. [Guio et al, 2012]). Однако в других исследованиях [Coromaldi and Zoli, 2012; Aaberge and Brandolini, 2014] отмечается, что показатели образования и занятости в большей степени относятся к факторам бедности, и потому при непосредственной оценке депривации их использовать не следует.

После отбора исходных показателей необходимо определиться с тем, как агрегировать их в сводный индекс. 
Процедура взвешивания отобранных показателей деприваций при расчете сводного индекса может быть различной, устоявшейся единой методики на текущий момен не предложено. В некоторых исследованиях используются равные веса, что равносильно предположению об одинаковом вкладе в бедность данного типа всех показателей (см. [Townsend, 2002; Alkire and Foster, 2011] и др.). В ряде случаев используются так называемые экспертные веса, когда соответствующие коэффициенты для различных показателей депривации определяются с помощью опросов экспертов, представителей социального блока исполнительной власти или населения (см. подробный обзор методов в [Decanc and Lugo, 2013]).

Альтернативу перечисленным способам определения весов представляют разнообразные статистические методы, когда данные «говорят сами за себя». В простейшем случае используются веса, рассчитанные с учетом распространенности тех или иных деприваций (т.е. более редкие виды лишений учитываются с большим весом). Более продвинутые методы, подробный обзор которых приводится в [Aaberge and Brandolini, 2014], определяют веса с учетом многомерного распределения данных. K числу таких подходов относится метод главных компонент, применяемый в данной работе. Иногда процедура взвешивания при оценке депривации применяется дважды: на первом шаге при агрегировании исходных данных в индексы деприваций по отдельным направлениям и затем при построении на их основе единого индекса.

Следующим шагом оценки является определение черты бедности - границы, отделяющих тех, кто испытывает депривацию данного типа, от всех остальных. Как отмечается [Coromaldi and Zoli, 2012], подобное разделение является еще менее объективным, чем в случае доходной бедности. Так, например, в России монетарная бедность определяется на основе прожиточного минимума, рассчитываемого с учетом цен и базовых потребностей людей с учетом пола и возраста. Для недоходной бедности понятие социальной нормы является существенно более зыбким и субъективным, его сложно формализовать подобно прожиточному минимуму. Иногда авторы выбирают черту депривации так, чтобы ее итоговая распространенность была примерно сопоставима с уровнем доходной бедности. В других исследованиях в качестве бедных рассматривается нижняя квинтиль (20\%) получившегося распределения [Tsakloglou and Papadopoulos, 2002; Coromaldi and Zoli, 2012].

\section{Данные и методика исследования}

Эмпирической основой данного исследования является репрезентативный опрос домохозяйств, в которых проживают ветераны труда, проведенный РАНХиГС в мае 2017 г. (1890 наблюдений). При определении лишений учитывалось мнение респондентов о том, насколько им необходимы те или иные товары или услуги, и в качестве депривации определялось лишь их «вынужденное отсутствие» (enforced lack).

Направления депривации и конкретные виды лишений, включенные в оценку, представлены в таблице 1.

\section{Таблица 1. Частота распространения деприваций, включенных} в оценку, среди ветеранов труда,\%

\begin{tabular}{|c|c|c|}
\hline Депривация & $\%$ & Показатель \\
\hline Недостаточное потребление фруктов & 32,3 & \multirow{4}{*}{ Питание } \\
\hline Недостаточное потребление мяса, птицы и рыбы & 23,7 & \\
\hline Высокая доля расходов на питание & 15,2 & \\
\hline Низкая оценка финансового положения & 3,4 & \\
\hline Малый размер сбережений & 43,8 & \multirow{4}{*}{$\begin{array}{l}\text { Финансовое } \\
\text { благосостояние }\end{array}$} \\
\hline Значительная задолженность & 7,4 & \\
\hline Значительная ипотечная нагрузка & 0,5 & \\
\hline Ограничение базовых материальных потребностей & 49,6 & \\
\hline Недостаточное потребление товаров длительного пользования & 14,7 & \multirow{2}{*}{ Имущество } \\
\hline Вынужденное отсутствие личного транспорта & 34,1 & \\
\hline Плохое здоровье & 6,4 & \multirow{6}{*}{ Здоровье } \\
\hline Наличие существенных ограничений в бытовой деятельности & 37,5 & \\
\hline Невозможность осуществлять работу по дому & 11,3 & \\
\hline Наличие существенных ограничений в мобильности & 25,5 & \\
\hline $\begin{array}{l}\text { Отсутствие мобильности (респондент не может самостоятельно } \\
\text { ходить в магазин) }\end{array}$ & 7,4 & \\
\hline Недостаточное потребление медицинских услуг и лекарств & 24,9 & \\
\hline Социально неприемлемый тип жилья & 5,5 & \multirow{6}{*}{ Жилье } \\
\hline Тесное жилье & 4,2 & \\
\hline Низкая самооценка качества жилья & 6,5 & \\
\hline Недостаточная оснащенность коммунальными удобствами & 17,4 & \\
\hline Холодное жилье & 9,7 & \\
\hline Жилье требует капитального ремонта & 38,6 & \\
\hline Одиночество & 10,0 & \multirow{3}{*}{$\begin{array}{l}\text { Социальная } \\
\text { включенность }\end{array}$} \\
\hline Недостаточная финансовая поддержка & 30,7 & \\
\hline Недостаточная помощь в быту & 10,7 & \\
\hline
\end{tabular}

Для построения совокупного индекса депривации была использована двухшаговая процедура: 1) построение шести индексов депривации по отдельным направлениям и 2) их агрегацию в совокупный индекс депривации. При агрегировании данных в индексы депривации по направлениям были применены два набора весов: равномерный, когда каждое лишение внутри данного направления учитывается с одинаковым весом, и оцененный 
с помощью метода главных компонент, т.е. с учетом вариации показателей лишений, включаемых в индекс. Результаты оценок показали высокую устойчивость к выбору весов, в связи с чем было принято решение использовать более интуитивно понятный равномерный метод.

Пороговый уровень рассчитывался в соответствии с неявно заданной социальной нормой, определяемой исходя из распределения количества лишений, испытываемых домохозяйствами выборки. Общая депривация оценивалась как ее наличие по как минимум четырем из шести направлений исследования.

\section{Недоходная бедность: \\ многообразие проявлений}

Несмотря на низкий уровень доходной бедности домохозяйств, в которых проживают ветераны труда (менее 5\% опрошенных домохозяйств), они часто испытывают разнообразные лишения, в том числе и имущественного характера. Примерно треть домохозяйств испытывают депривацию в целом, то есть сталкиваются с лишениями как минимум по четырем из шести выбранных направлений (табл. 2).

Таблица 2. Распределение домохозяйств в зависимости от видов испытываемых ими деприваций,\% взвешенной выборки

\begin{tabular}{|l|c|}
\hline \multicolumn{1}{|c|}{ Вид депривации } & Доля респондентов, \% \\
\hline Нет депривации & 22,5 \\
\hline По питанию & 30,2 \\
\hline По финансовому благосостоянию & 32,8 \\
\hline По имуществу & 38,2 \\
\hline По жилью & 19,9 \\
\hline По здоровью & 33,2 \\
\hline По социальной включенности & 38,9 \\
\hline Депривация в целом & 18,6 \\
\hline Доходы ниже прожиточного минимума & 4,4 \\
\hline
\end{tabular}

Пожилые люди часто вынуждены ограничивать себя в потреблении фруктов (32\% опрошенных), а также мяса и рыбы (24\%).

Распространенность лишений по питанию существенно зависит от типа домохозяйств, причем определяющим фактором является наличие в семье работающих (рис. 1). Что касается возраста опрошенных, то можно отметить лишь значительное снижение распространенности лишений по питанию среди наиболее молодых респондентов (до 55 лет).

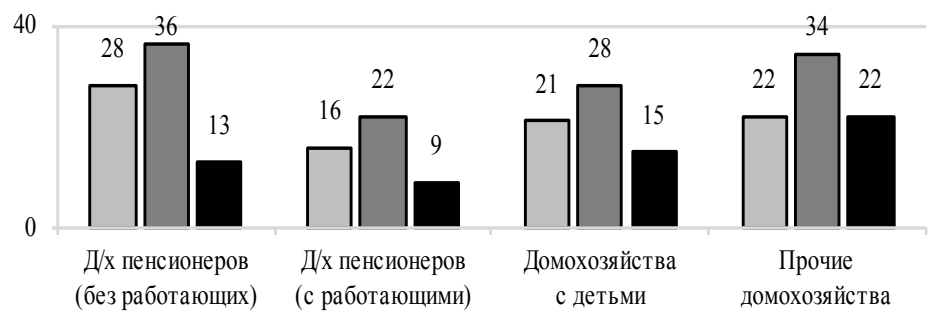

口Недостаточное потребление мяса, птицы и рыбы

口Недостаточное потребление фруктов

Высокая доля расходов на питание

Рис. 1. Распространенность лишений, включенных в интегральную оценку депривации по питанию и финансовому благополучию, среди различных типов домохозяйств,\%

Домохозяйства пожилых почти не имеют долгов по платежам и кредитам, но часто отказывают себе в том, что принято относить к базовым материальным потребностям (замена мебели, покупка одежды и обуви, отдых и досуг) - эти проявления депривации испытывают 44\% и 50\% опрошенных соответственно.

Распространенность этих лишений столь велика, что они в известном смысле и не являются отклонением от социальной нормы для пожилых граждан России. Другой важной особенностью людей старшего возраста, к которым в основе своей относятся домохозяйства с ветеранами труда, является низкий уровень долговой нагрузки - лишь 7\% опрошенных имеют долги или неоплаченные кредиты или платежи.

Состав домохозяйства оказывает существенное влияние на распространенность лишений, связанных с финансовым благополучием (рис. 2). Для домохозяйств пожилых (одиночки и семейные пары) определяющим является фактор наличия в домохозяйстве работающих. Также можно отметить относительно высокую распространенность разнообразных видов задолженности среди семей с детьми (17\%). 
60

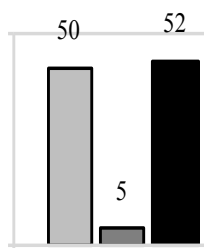

Д/х пенсионеров (без работающих)

2

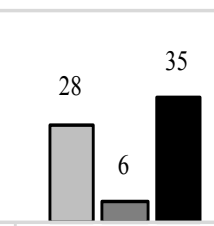

Д/х пенсионеров

(с работающими)
57

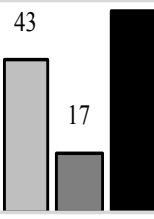

Домохозяйства

с детьми

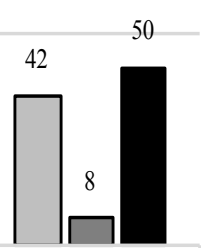

Прочие

домохозяйства
口Малый размер сбережений

口Значительная задолженность

Ограничение базовых материальных потребностей

Рис. 2. Распространенность лишений, включенных в интегральную оценку депривации по финансовому благосостоянию, в зависимости от типа домохозяйств, \%

Главный фактор депривации в сфере жилья - проживание в сельской местности или небольших городах.

Большинство лишений, использовавшихся при определении депривации домохозяйств по жилью, являются относительно редкими. Так, доля домохозяйств, проживающих в общежитиях или коммунальных квартирах, в среднем по выборке составляет $6 \%$, оценивающих свое жилье как плохое или очень плохое $-7 \%$, проживающих в холодном жилье - $10 \%$. Низкая распространенность тесного проживания (4\%) вполне естественна, когда основу выборки составляют домохозяйства из одного-двух человек. Нехватка базовых коммунальных удобств была зафиксирована у 17\% домохозяйств, и лишь необходимость капитального ремонта, которую в большей степени следует воспринимать как свидетельство плохого состояния дома, в котором находится жилье, отмечалась респондентами в $39 \%$ случаев.

Главным фактором различий в депривации домохозяйств по жилью является проживание в сельской местности или в небольших городах и поселках, где нехватка базовых коммунальных удобств широко распространена (рис. 3).

Пожилые люди часто вынуждены отказываться от покупки необходимых лекарств и медицинских услуг, а в более старших возрастах остро нуждаются в помощи по хозяйству.

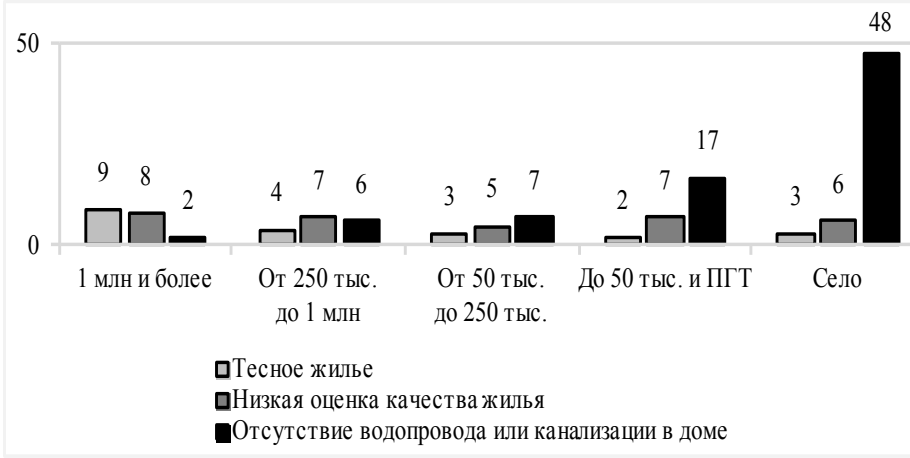

Рис. 3. Распространенность лишений, включенных в интегральную оценку депривации по жилью, в зависимости от размера населенного пункта проживания домохозяйств,\%

Ключевыми факторами наличия у респондентов различных деприваций по здоровью являются возраст и самооценка здоровья. Доступность лекарств и медицинских услуг также существенно зависит от доходов домохозяйства. Как показано на рисунке $4,32 \%$ домохозяйств первой, беднейшей квинтильной группы были вынуждены отказываться от покупки необходимых лекарств и услуг из-за нехватки средств (для сравнения: среди наиболее богатых домохозяйств - 15\%).

40

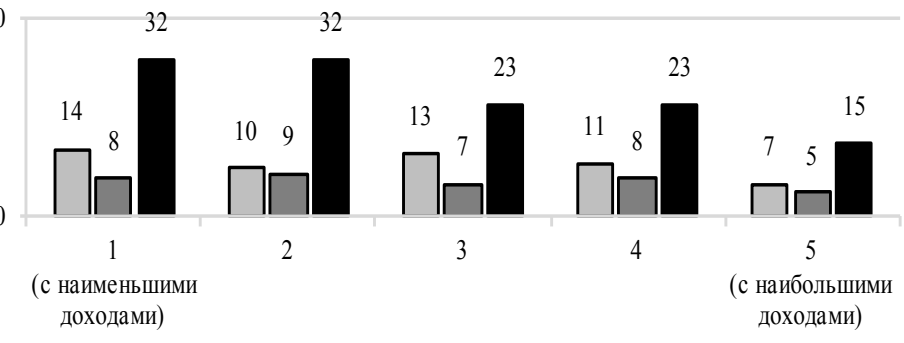

口Невозможность работыпо дому Отсутствие мобильности

-Недостаточное потребление лекарств

Рис. 4. Распространенность лишений, включенных в интегральную оценку депривации по здоровью, в зависимости от доходов домохозяйств (квинтильные группы), \% 
В старшей возрастной группе наблюдается существенный рост неспособности респондентов к самообслуживанию: $24 \%$ опрошенных не способны самостоятельно осуществлять необходимую работу по дому, а $15 \%$ - не в состоянии дойти до магазина. Ограничения в доступности лекарств также высоки - четверть опрошенных в возрасте от 75 лет и старше сталкивались с необходимостью отказаться от покупки необходимых лекарств или медицинских услуг (рис. 5).

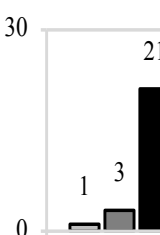

До 55 лет

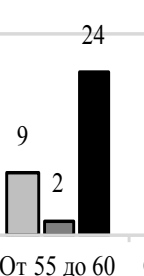

лет
26
28

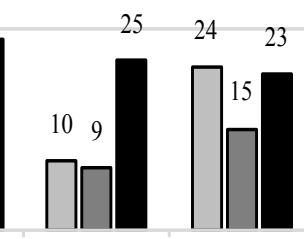

От 70 до 75 Старше 75 лет
口Невозможность работы по дому

口Отсутствие мобильности

-Недостаточное потребление лекарств

Рис. 5. Распространенность лишений, включенных в интегральную оценку депривации по здоровью, в зависимости от возраста проживающих в домохозяйствах ветеранов труда,\%

Респонденты с плохим здоровьем часто страдают от недостаточного потребления медицинских товаров и услуг: $31 \%$ опрошенных, оценивающих свое здоровье как «скорее плохое» и $39 \%$ из оценивающих как «очень плохое», за последний год оказывались в ситуации, когда им приходилось отказываться от необходимых лекарств или услуг.

Среди проблем социальной интеграции пожилые чаще всего называют недостаточную финансовую поддержку; кроме того, с возрастом усиливается чувство одиночества.

Среди факторов, способствующих росту рисков лишений, связанных с недостаточной социальной интеграцией, можно выделить возраст, отсутствие партнера и низкие доходы. Так, например, чувство одиночества гораздо чаще испытывают одиночки - 24\% опрошенных (для сравнения: пожилые семейные пары - 9\%) (рис. 6).

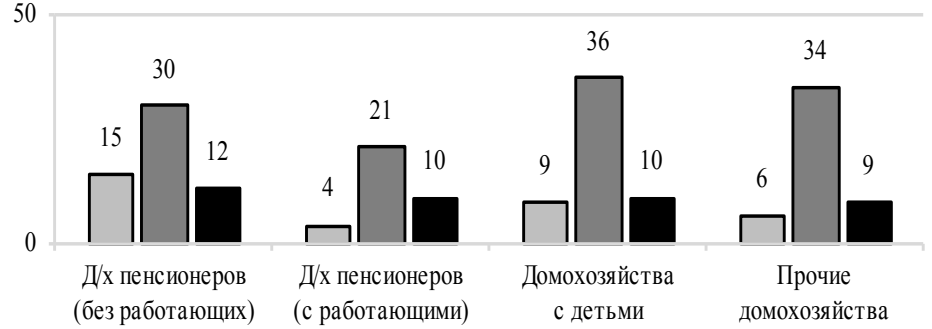

口Чувство одиночества

口Недостаточная финансовая поддержка

口Недостаточная помощь в быту

Рис. 6. Распространенность лишений, включенных в интегральную оценку депривации по социальной интеграции, в зависимости от типа домохозяйств,\%

С возрастом социальная исключенность растет. В частности, качественный скачок в ощущении одиночества происходит в старшей возрастной группе: с 3-5\% в возрасте до 65 лет до $10-11 \%$ в возрасте от 65 до 75 лет и 19\% в возрасте старше 75 лет (рис. 7).

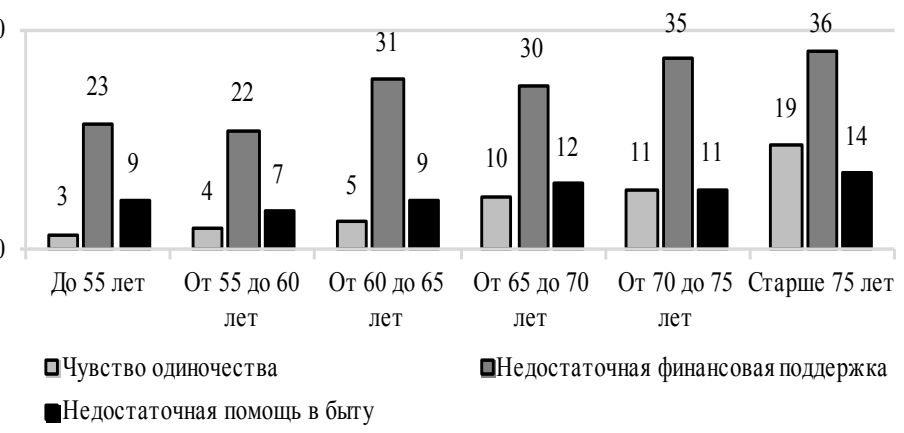

Рис. 7. Распространенность лишений, включенных в интегральную оценку депривации по социальной интеграции, в зависимости от возраста проживающих в домохозяйствах ветеранов труда,\%

Рост ощущения недостаточной финансовой поддержки начинается несколько раньше, в возрасте от 60 лет и старше, совпадая с возрастом массового выхода на пенсию. Недостаточная помощь 
в быту наиболее остро воспринимается в старших возрастах, о ней заявили $14 \%$ опрошенных в возрасте от 75 лет и старше.

Состояние здоровья, измеренное с помощью самооценки респондентов, существенно влияет на распространенность лишений, связанных с недостаточной социальной интеграцией опрошенных (рис. 8). Ветераны труда с очень плохим здоровьем чаще страдают от недостаточной финансовой поддержки $(47 \%$ против $31 \%$ в среднем по выборке), испытывают чувство одиночества $(25 \%$ против $10 \%)$ и сталкиваются с недостатком помощи в быту ( $16 \%$ против $11 \%$ в среднем по выборке).
50 0
Скорес

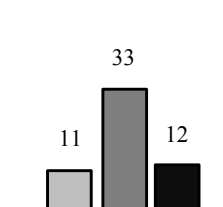

Скорее плохое

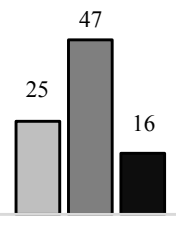

Очень плохое

口Чувство одиночества

口Недостаточная финансовая поддержка

Рис. 8. Распространенность лишений, включенных в интегральную оценку депривации по социальной интеграции, в зависимости от самооценки здоровья проживающих в домохозяйствах ветеранов труда,\%

Предварительный анализ взаимосвязи состояния депривации и различных характеристик респондентов и домохозяйств, в которых они проживают, позволил выдвинуть гипотезы о значимости влияния на риски депривации таких факторов, как тип населенного пункта, состав домохозяйства, а также индивидуальные характеристики опрошенных ветеранов труда (возраст, уровень образования, самооценка здоровья и др.). Гипотезы количественного исследования были протестированы методом регрессионного анализа.

\section{Что влияет на недоходную бедность пожилых?}

Для оценки влияния характеристик домохозяйства на вероятность его попадания в состояние того или иного вида депривации была использована пробит-модель бинарного выбора:

$$
P\left(y_{t}=1\right)=\Phi\left(x_{t}^{\prime} \beta\right)
$$

где $y_{t}$ - переменная, соответствующая наличию у семьи $t$ депривации данного вида, $x_{t}$ - вектор факторов, характеризующих эту семью, а $\Phi$ - функция стандартного нормального распределения.

Применение регрессионного анализа позволяет определить значимость и характер влияния того или иного фактора при сохранении прочих характеристик, включенных в модель, неизменными. Всего было рассмотрено семь зависимых переменных, соответствующих наличию у домохозяйств деприваций по шести направлениям исследования и депривации в целом. Предварительный отсев независимых переменных был осуществлен с помощью анализа попарных корреляций. Из анализа были исключены переменные с размером корреляции, превышающим 0,3. В таблице 3 приводятся значения предельных эффектов независимых факторов, включенных в исследование*.

Как показали расчеты, риск различных деприваций существенно зависит от типа домохозяйства, в котором проживает ветеран труда, его индивидуальных характеристик (состояния здоровья, возраста, уровня образования) и в меньшей степени от типа населенного пункта.

Tип населенного пункта. Проживание в городской местности снижает риск общей депривации, в основном за счет меньшей депривации по жилью-здесь эффект большей доступности в городе коммунальных удобств пересиливает эффект плотности проживания.

Эффект снижения рисков депривации в связи с проживанием в городе наиболее сильно проявляется в случае жителей крупнейших городов (с населением от 1 млн чел. и выше). Так, вероятность испытывать депривацию по питанию здесь ниже на 5\%, чем для жителей села, по здоровью - на 9\% ниже, а депривацию по имуществу - на 7\%.

Состав домохозяйства. Риски депривачии ниже для семейных nар и домохозяйств с работающиими. Наиболее благополучной категорией домохозяйств с ветеранами труда являются пожилые семейные пары и домохозяйства работающих одиночек.

Наличие в домохозяйствах работающих лиц существенно снижает риски различных деприваций, прежде всего связанных с доходами и имуществом. Так, например, для семейных пар с как минимум одним работающим вероятность депривации по питанию на 17\% ниже, чем для прочих домохозяйств без работающих, по финансовому благосостоянию - на $23 \%$, по имуществу - на 15\% ниже.

*** $\mathrm{p}<0,01 ; * * \mathrm{p}<0,05 ; * \mathrm{p}<0,1$ 


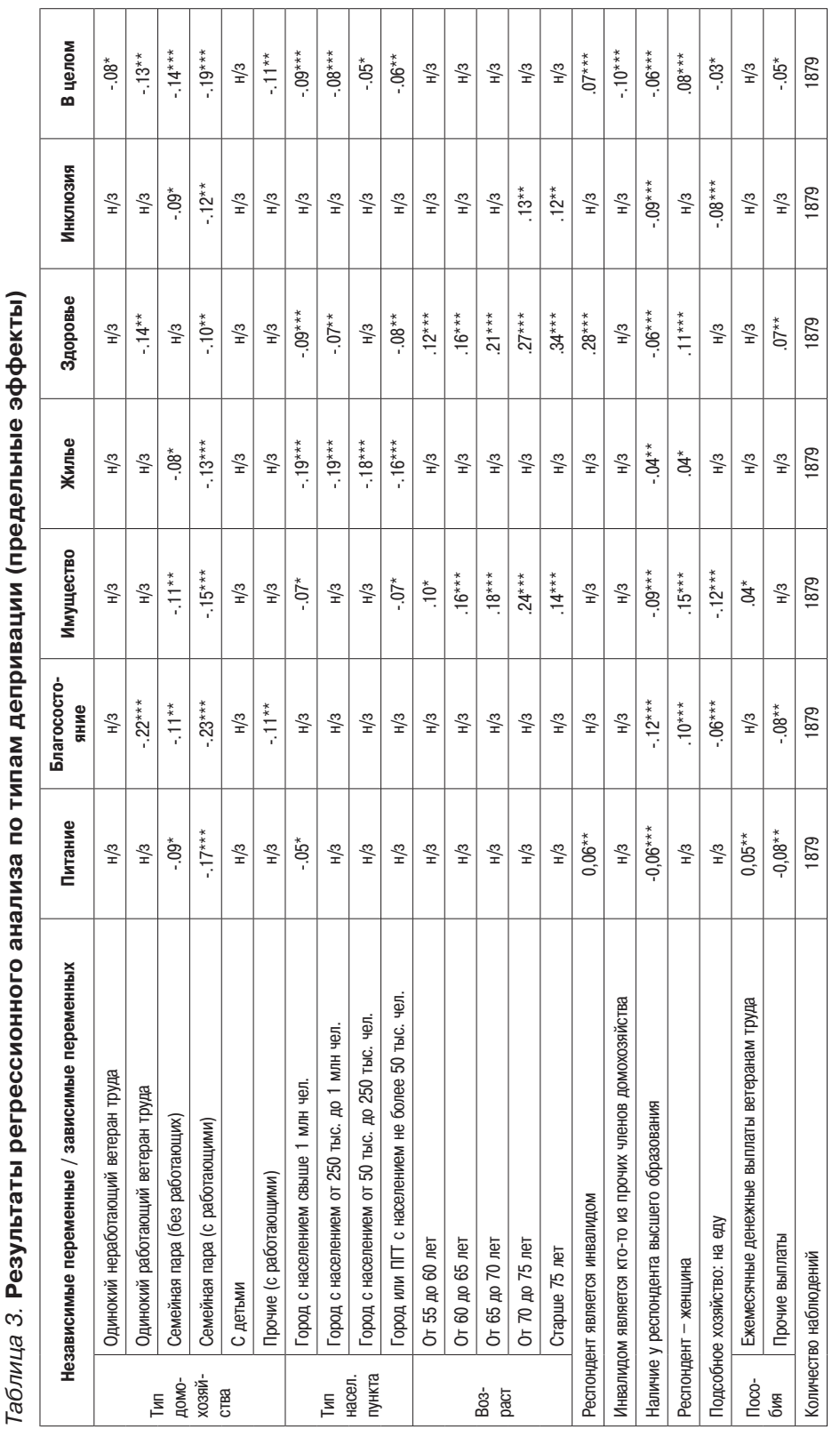

Ведение подсобного хозяйства в целом позволяет домохозяйству снизить риски различных деприваций, в частности финансового неблагополучия, депривации по имуществу и даже вероятность социальной исключенности. Данный фактор может сочетать в себе различные наблюдаемые и ненаблюдаемые характеристики домохозяйства (в том числе наличие участка земли, мобильность и наличие социальных связей).

Индивидуальные характеристики респондентов. Высшее образование существенно способствует снижению деприваций всех видов; с возрастом растут риски депривации по здоровью. Ключевым фактором профилактики многомерной бедности является высшее образование респондентов, которое заметно снижает риски всех изучаемых видов депривачии.

Гендерная принадлежность респондента также является значимым фактором: женщины - ветераны труда сталкиваются с более высокими рисками депривации по финансовому благополучию, имуществу и здоровью по сравнению с мужчинами при сохранении прочих факторов равными.

Больший возраст респондентов ожидаемо увеличивает риски депривации по здоровью. Особенно это касается ограничений в работе по дому и мобильности (более $55 \%$ респондентов в возрасте старше 75 лет испытывают трудности в работе по дому, а $45 \%$ - при совершении покупок в магазине).

Отдельного упоминания заслуживает тема социальной исключенности ветеранов труда, поскольку вопросы, необходимые для оценки депривации данного типа, редко задаются в рамках стандартных обследований уровня жизни и здоровья населения. Согласно полученным результатам, чаще сталкиваются с проблемами в сфере социальной интеграции люди старше 70 лет. Наличие у ветерана труда супруга значимо снижает риски социальной депривации. Кроме того, более социально интегрированными считают себя респонденты с высшим образованием высокий уровень образования значимо снижает риски всех видов деприваций, оцениваемых в данном исследовании.

\section{Заключение}

Согласно современной концепции бедности как многопланового явления, низкие доходы - это лишь одно из ее проявлений. 
Несовершенство определения бедности с помощью доходов особенно чувствуется при изучении депривации пожилых.

В проведенном исследовании на данных репрезентативного обследования ветеранов труда были даны оценки недоходной бедности по шести направлениям, включая питание, финансовое благосостояние, имущество, жилье, здоровье и социальную интеграцию. Как показывают результаты исследования, низкий уровень доходной бедности маскирует существенные проблемы, с которыми сталкиваются представители старших возрастов, несбалансированное питание, недостаточные сбережения, невозможность регулярно покупать одежду, обувь и предметы быта, одиночество и нехватку помощи в быту.

В то же время следует отметить, что домохозяйства, в которых проживают ветераны труда, крайне неоднородны с точки зрения подверженности различным видам деприваций. Наиболее благополучной категорией с точки зрения рисков недоходной бедности являются пожилые семейные пары и домохозяйства работающих одиночек.

Ключевой индивидуальный фактор, снижающий риски многомерной бедности, - высшее образование респондентов. Больший возраст опрошенных ожидаемо увеличивает риски депривации по здоровью, особенно в плане ограничений в работе по дому и мобильности.

Проживание в городской местности снижает риски общей депривации, в основном за счет существенно меньшей вероятности депривации по жилью - здесь эффект большей доступности в городе коммунальных удобств пересиливает эффект плотности проживания.

С проблемами в сфере социальной интеграции чаще всего сталкиваются люди старшего возраста (от 70 лет и старше). Наличие у ветерана труда супруга значимо снижает риски социальной депривации.

\section{Литература/References}

Бедность: альтернативные подходы к определению и измерению. Авт. коллектив /Под ред. Т. Малевой. М.: Московский центр Карнеги, 1998 [Bednost” al'ternativnye podhody k opredelenju i izmerenyu (1998). Avt. кollektiv. Pod red. T. Malevoj. Moskovskij Karnegy centr.

Овчарова Л.Н. Теоретико-методологические вопросы определения и измерения бедности. SPERO. 2012. № 16. C. 15-38.[Ovcharova L. N. (2012).
Teoretiko-metodologicheskie voprosy opredelenja i izmerenija bednosty. SPERO № 16. Pp. 15-38].

Aaberge, R., Brandolini, A. (2015). Multidimensional Poverty and Inequality. In A. B. Atkinson \& F. Bourguignon (Eds.), Handbook of income distribution, Chapter 3. Pp. 141-216). Amsterdam: Elsevier.

Alkire S., Foster J. (2011). Counting and multidimensional poverty measurement/. Journal of Public Economics, Elsevier. Vol. 95(7). Pp. 476-487.

Alkire S., Santos M. (2010). Acute Multidimensional Poverty: A New Index for Developing Countries, Human Development Research Papers (UNDP).

Atkinson A., Cantillon B., Marlier E., Nolan B. (2002). Social indicators: The EU and social inclusion. Oxford: Oxford University Press.

Bourguignon F., Chakravarty S. R. (2003). The measurement of multidimensional poverty. Journal of Economic Inequality. Vol.1. Pp. 25-49.

Coromaldi M., Zoli M. (2012). Deriving Multidimensional Poverty Indicators: Methodological Issues and an Empirical Analysis for Italy. Social Indicators Research. Vol. 107. Pp. 37-54.

Decanc K., Lugo M. (2013). Weights in Multidimensional Indices of Wellbeing: An Overview. Econometric Reviews, Taylor \& Francis Journals. Vol. 32(1). Pp. 7-34 Guio A.-C., Gordon D., Marlier E. (2012). Measuring Material Deprivation in the EU: Indicators for the Whole Population and Child-Specific Indicators, Eurostat Methodologies and Working Papers (OPOCE).

Ravallion M. (2011). On Multidimensional Indices of Poverty. Policy Research working paper. no. WPS5580, World Bank.

Townsend P. (2002). Poverty, Social Exclusion, and Social Polarisation: The Need to Construct and International Welfare State. P. Townsend and D. Gordon (Eds.) World Poverty, New Policies to Defeat an Old Enemy. Bristol, UK. Policy Press.

Tsakloglou P., Papadopoulos F. (2002). Aggregate level and determining factors of social exclusion in twelve European countries. Journal of European Social Policy. Vol. 12 (3). Pp. 211-225.

United Nations Development Programme. (2016). Human development report 2016: Sustaining human progress. Development for Everyone.

Статья поступила 02.02.2018.

\section{Summary}

Kuznetsova P. Institute for Social Analysis and Prediction RANEPA, Moscow Non-Monetary Poverty of the Elderly

In this research we estimate non-monetary poverty of the elderly on the data of a representative survey of labor veterans. We consider six areas of deprivation (food, financial welfare, property, housing, health and social integration) as well deprivation in total. Despite the low level of income poverty, senior citizens often have to restrict themselves in food as well as in consumption of medicines and medical services, suffer from a lack of financial support and assistance in everyday life. The risks of nonmonetary poverty increase with the age of respondents, while having a partner, living in a household with a working person, as well as high level of education significantly reduce them significantly.

Poverty; deprivation; elderly; poverty risks, social exclusion; multidimensional analysis 